\title{
PENGARUH TRUST DAN COMMITMENT TERHADAP RELATIONSHIP QUALITY Studi pada Perusahaan Pasangan Usaha PT. XYZ (Sebuah Lembaga Keuangan Non Bank)
}

\author{
Reza Rahardian \\ Fakultas Ekonomi, Universitas Sebelas Maret
}

\begin{abstract}
This study aims to describe the business partner companies perceived of trust, commitment and relationship quality at PT. XYZ (a non bank financial institution). Theoritically, this research aims to provide empirical evidence of the influence of trust and commitment on relationship quality, and the mediation effect of commitment to the influence of trust towars the relationship quality. Data were gathered from 31 business partner companies of PT. XYZ. Multiple Regression/Path Analysis was used to test the hypotheses. Descriptive analysis shows that there is a high trust and commitment in business partner companies of PT. XYZ. They also give a high respons to the relationship quality. Regression analysis shows that trust and commitment influence the relationship quality. It also revealed that there isi mediation effect of commitment to the influence of trust towards relationship quality. This study has limitation by using respondent perceived only. This can be overcome by conducting comparative analysis using actual performance indicator evaluated by PT. XYZ.
\end{abstract}

Keywords : Trust, Commitment, Relationship Quality

\section{PENDAHULUAN}

Beberapa studi telah mengungkap bukti empiris tentang pengaruh praktek supply chain management terhadap kinerja perusahaan. Kesimpulan yang didapatkan dari beberapa literatur adalah bahwa integrasi pembelian memiliki dampak positif pada kinerja perusahaan. Pentingnya kerja sama supplier dengan dealer yang dibina dengan baik semakin disadari perusahaan, tidak hanya untuk kepentingan dalam jangka pendek tetapi juga untuk jangka panjang. Perusahaan dapat memperoleh banyak keuntungan dari kerja sama jangka panjang. Hal ini dirasakan dalam kondisi ketika dealer membutuhkan kiriman bahan baku untuk kebutuhan mendesak, supplier dapat segera memenuhi permintaan tersebut, karena hubungan yang telah terbina dengan baik selama ini. Hubungan baik supplier dengan dealer juga akan memberikan keuntungan pada ongkos pengiriman yang stabil, sehingga dapat mengurangi biaya secara lebih efisien.

Salah satu faktor yang mempengaruhi stabilitas suatu hubungan adalah tingkat kepercayaan. Hubungan bisnis yang kooperatif akan tumbuh seiring meningkatnya kepercayaan dan komitmen di antara mitra bisnis. Beberapa penelitian empirik mengkaji tentang hubungan kerja sama jangka panjang (Landeros dan Monczska, 1989; Lorange dan Roos, 1991; Burt dan Doyle, 1993) dan penelitian tersebut menghasilkan temuan bahwa yang mengimplementasikan supply chain management dapat mengembangkan hubungan baik dengan suppliernya. Guinipero dan Brand (1996) secara empirik juga menemukan bahwa sebuah perusahaan dengan supply chain yang dikelola dengan baik dan kuat terbukti dapat menjaga keberlangsungan hubungan dan membantu pengembangan rencana ke depan dengan para pemasok.

Menurut Zineldin et al. (1997), kualitas sebuah hubungan merupakan fungsi dari beberapa elemen atau faktor-faktor tertentu di antaranya: kooperasi, kemampuan dan kinerja karyawan termasuk manajer, sumber daya fisik, kualitas, distribusi dan penentuan harga produk, pembagian informasi, pengalaman, harapan konsumen dan kepuasan. 
Dalam konteks hubungan supplier dengan dealer, evaluasi dealer tentang tingkat kepercayaan dan komitmen akan berdasarkan pada sudut pandang yang lebih luas menyangkut keseluruhan kinerja supplier-nya.

Persaingan antar lembaga keuangan dalam menyediakan pendanaan bagi berbagai jenis usaha semakin ketat. Hal ini diindikasikan dengan cukup banyaknya jumlah lembaga keuangan serta semakin beragamnya produk yang ditawarkan oleh masing-masing lembaga keuangan tersebut. Salah satu lembaga bergerak di bidang keuangan dan pendanaan adalah PT. XYZ (Sebuah Lembaga Keuangan Non Bank). Dalam menghadapi persaingan tersebut, trust dan commitment menjadi salah satu kunci untuk dapat meningkatkan kualitas hubungan antara PT. XYZ dengan Perusahaan Pasangan Usahanya. Dengan semakin meningkatnya trust dan commitment, diharapkan kualitas hubungan antara PT. XYZ dengan Perusahaan Pasangan Usaha juga semakin meningkat dan pada akhirnya akan menjamin keberlanjutan masing-masing perusahaan.

Penelitian ini berorientasi pada Perusahaan Pasangan Usaha PT. XYZ, yang terdiri atas Usaha Kecil, Mikro dan Menengah, dengan salah satu bentuknya adalah usaha retail. Retail adalah semua usaha bisnis yang secara langsung mengarahkan kemampuan pemasarannya untuk memuaskan konsumen akhir berdasarkan organisasi penjualan barang dan jasa sebagai inti dari distribusi (Gilbert, 2003). Hal ini menyebabkan Perusahaan Pasangan Usaha akan berusaha untuk selalu memelihara hubungan supply chain (salah satunya dengan PT. XYZ sebagai lembaga pembiayaan), untuk dapat meningkatkan kinerja perusahaan.

\section{TINJAUAN PUSTAKA}

Trust

Trust merupakan suatu hal yang penting dalam sebuah komitmen, dan komitmen akan mempunyai arti jika dapat terwujud. Trust dan komitmen merupakan hasil pengembangan dari hubungan kolaboratif antara dua perusahaan. Trust membutuhkan waktu untuk berkembang dengan berbagai faktor yang dapat mempengaruhinya. Suatu organisasi harus mampu mengenali faktor-faktor yang dapat membentuk trust agar dapat menciptakan, mengatur, memelihara, menyokong dan mempertinggi tingkat hubungan dengan pelanggan (Zineldin, et al., 1997; Zineldin, 1998). Sementara itu hasil penelitian Schurr dan Ozonne (1985) menunjukkan bahwa dalam situasi penawaran antara penjual dan pembeli, trust merupakan hasil utama dari proses pemecahan masalah secara kooperatif dan dialog-dialog yang dibina.

\section{Commitment}

Commitment, seperti halnya dengan trust juga menyatakan secara langsung, terbuka, dan apa adanya tentang rahasia perusahaan, diluar kepentingan untuk merencanakan penyusunan sebuah hubungan. Tetapi commitment secara tidak langsung menyatakan bahwa trust yang akan diberikan kepada mitra kerjanya terbatas pada integritas tertentu. Commitment dan perilaku bertanggung jawab seperti halnya trust tidak bisa dibuat-buat/ dipaksa, tetapi harus dihasilkan. Mengembangkan sebuah hubungan bisnis yang dapat dipercaya mungkin membutuhkan proses jangka panjang, yang berlangsung tahap demi tahap, resiko dan ketidakmenentuan berkurang, sedangkan komitmen dan trust meningkat (Zineldin, et al., 1997).

\section{Relationship Quality}

Relationship quality telah dibahas sebagai bundel dari yang nilai tak terukur meningkatkan jasa atau produk dan mengakibatkan suatu diharapkan pertukaran antara para penjual dan para pembeli ( Levitt, 1986). Konsep umum tentang relationship quality menguraikan 
keseluruhan iklim dan kedalaman dari suatu hubungan ( Johnson, 1999). Menurut Jarvelin dan Lehtinen (1996) relationship quality mengacu pada suatu persepsi pembeli dari seberapa baik keseluruhan hubungan memenuhi harapan, ramalan, keinginan dan gol pelanggan mempunyai mengenai keseluruhan hubungan. Realationship quality antara konsumen dan perusahaan didefinisikan sebagai derajat kesesuaian dari suatu hubungan relasi untuk memenuhi kebutuhan konsumen yang tergolong dalam hubungan relasi tersebut.

Gummesson ( 1987b) mengidentifikasi dua dimensi dari relationship quality pada jasa/layanan. la menggambarkannya sebagaihubungan sosial dan hubungan profesional. Crosby et al. ( 1990) mempelajari berbagai aspek dari relationship quality dan mempersepsikannya dalam kepercayaan pembeli pada penjual dan kepuasan dalam. Oleh karena itu, relationship quality yang tinggi berarti bahwa pelanggan bisa bersandar pada jasa/layanan integritas supplier dan mempunyai keyakinan pada kinerja masa depan sebab tingkat kinerja masa lalu yangmemuaskan.. Di samping itu, riset yang diselenggarakan oleh Bejou et al. ( 1996) menyimpulkan bahwa relationship quality antara penjual-pelanggan itu adalah suatu prasyarat yang penting bagi suatu kesuksesan hubungan jangka panjang.

Hasil Penelitian-Penelitian Terdahulu

Beberapa studi telah banyak membahas tentang pentingnya kepercayaan dan komitmen dalam sebuah hubungan kerjasama. Bahwa kesuksesan suatu hubungan tergantung pada beberapa bentuk perubahan yang dikarakteristikkan oleh tingkat kepercayaan yang tinggi adalah salah satu hasil penelitian yang dilakukan oleh Dweyer (1987); Morgan dan Hunt(1994); Ellram (1995); Smeltzer (1997). Selain itu, Zineldin (1999) menyatakan bahwa kualitas suatu hubungan adalah fungsi dari beberapa faktor atau elemen, diantaranya: kooperasi, kemampuan dan kinerja karyawan termasuk manajer, sumber daya fisik, pengiriman dan pemberian harga produk/ jasa, pertukaran informasi, pengalaman, harapan dan kepuasan konsumen.

Memunculkan paradigma baru dalam suatu hubungan sama artinya dengan melakukan aktifitas yang berkaitan dengan pengembangan dan pengaturan agar perubahan hubungan bisa berhasil (Morgan dan Hunt, 1994). Menciptakan hubungan kolaboratif dengan supplier sebagai suatu model dominan dari suatu interaksi adalah sangat berlawanan dengan konsep tradisional, hampir berlawanan dalam interaksi antara penjual dan pembeli (Guinipero dan Brand, 1996), tapi konsep seperti hubungan kolaboratif telah lama diterima oleh supplier dan customers.

Banyak manfaat yang potensial dari hubungan jangka panjang (Ellram, 1995; Zineldine, 1998). Supplier jangka panjang misalnya, akan lebih tertarik pada kebutuhan konsumen akhir. Bukti bahwa hubungan kolaboratif yang berhasil tergantung pada perubahan bentuk hubungan yang dikarakteristikkan oleh tingkat kepercayaan yang tinggi dan dapat ditentukan oleh tingkat rata-rata faktor yang tidak mempunyai peranan penting pada hubungan (Ellram, 1995).

Penelitian yang dilakukan oleh Zineldin (2000) yaitu menguji pengaruh faktor-faktor utama terhadap trust dan commitment dalam hubungan antar supplier dengan dealer: sebuah studi empiris pada industri kayu di Swedia. Penelitian tersebut menguji pentingnya beberapa variabel tertentu, seperti kemauan supplier untuk beradapatasi dengan dealer, membangun kekuatan hubungan, biaya menghentikan/ mengakhiri suatu hubungan, tingkat pembagian nilai, komunikasi formal/ informal antar bagian, perilaku menguntungkan dari supplier, dan tingkat kepuasan suatu hubungan, untuk memberikan tingkat kepercayaan dan komitmen yang tinggi dalam suatu hubungan. 
Penelitian lebih lanjut yang dilakukan oleh Wong (2002) yaitu menguji pengaruh trust dan commitment terhadap relationship quality dalam hubungan antara seller dengan customer: sebuah studi empiris pada bisnis retail di Victoria, Australia. Pada penelitian Wong, Riset yang dilakukan oleh Wong di sini menyediakan suatu penyelidikan ke dalam konsep dari komitmen dan kepercayaan, di dua tingkat hubungan eceran: penjual mengukur seperti halnya tingkatan toko, dan menguji dampak mereka di mutu hubungan. Penemuan ini usahakan suatu perspektif yang diperluas di riset manajemen hubungan pelanggan. Penemuan dari riset ini yang diungkapkan peran dari trust dan commitment dan dampak mereka di relationship quality.

Perbedaan penelitian sekarang dengan penelitian-penelitian terdahulu yaitu pada pada penelitian-penelitian sebelumnya, topik yang diteliti mengenai hubungan antara seller dengan customer. Oleh karena itu peneliti tertarik untuk meneliti bagaimana pelaksanaan hubungan antara seller dengan supplier pada bisnis retail yang dipengaruhi oleh trust dan commitment. Mengingat dalam industri ini hubungan dengan supplier sangat mempengaruhi kinerja.

Kerangka pemikiran dari penelitian ini dapat dijelaskan sebagai berikut:

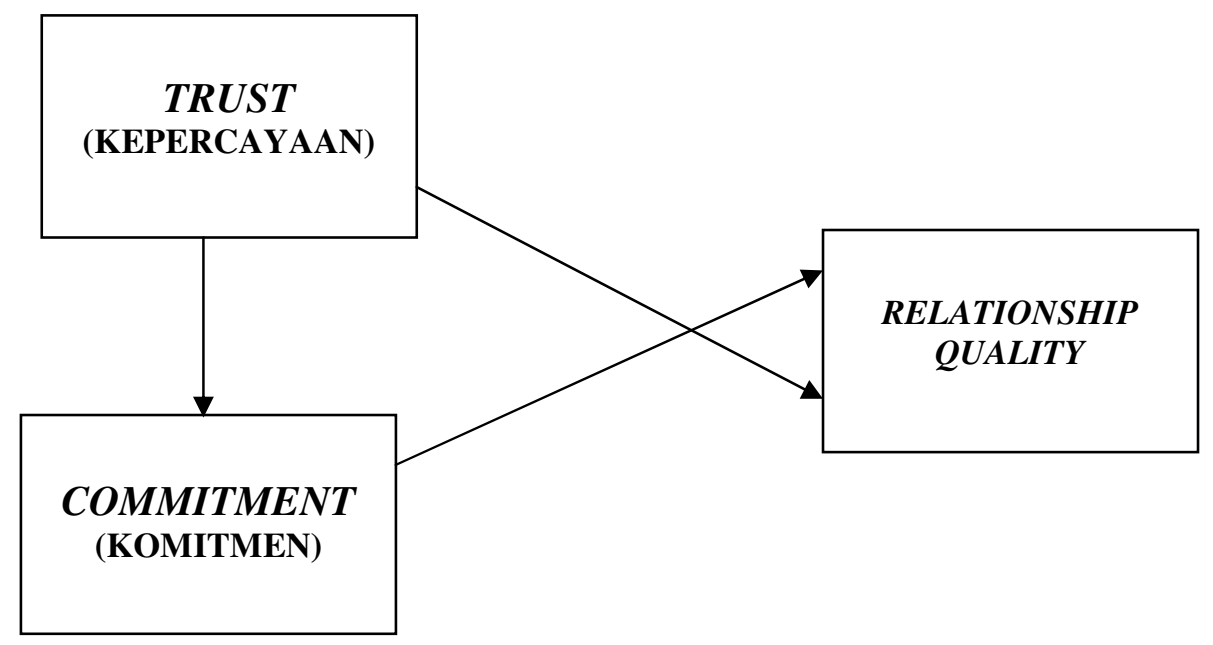

GAMBAR 1. Skema Kerangka Pemikiran

Dari gambar 1, dapat diketahui bahwa model dalam penelitian ini terdiri dari tiga tahap. Tahap pertama menganalisis pengaruh antara trust terhadap relationship quality yang terbentuk antara supplier dengan dealer.

Tahap ke dua menganalisis pengaruh antara commitmentt dengan relationship quality dalam hubungan supplier dengan dealer.

Tahap ke tiga menganalisis pengaruh commitment sebagai pemediasi dalam hubungan antara trust dengan relationship quality.

\section{PENGEMBANGAN HIPOTESIS}

Penelitian Wong dan Sohal (2002) mengemukakan serangkaian hasil penting terkait dengan hubungan antara trust dan commitment terhadap relationship quality. Wong dan Sohal membuktikan adanya hubungan antara trust dan commitment dengan relationship quality. Di antara trust dan commitment, commitment merupakan faktor yang paling kuat mempengaruhi relationship quality. Temuan Wong dan Sohal ini mendukung penelitian 
sebelumnya yang dilakukan oleh Swan dan Nolan (1985)serta Ford (1990) dan $\mathrm{Ha}^{\circ}$ kansson (1982)

Berdasarkan penelitian terdahulu tersebut, maka hipotesis yang diajukan dalam penelitian ini dirumuskan sebagai berikut:

$\mathrm{H1}$ : Ada pengaruh antara trust terhadap relationship quality.

H2: Ada pengaruh antara commitment terhadap relationship quality.

H3: Ada pengaruh mediasi commitment dalam hubungan antara trust dengan relationship quality.

\section{METODE PENELITIAN}

Desain Penelitian

Bentuk penelitian yang digunakan adalah penelitian deskriptif dan verifikative. Penelitian deskriptif dilakukan untuk memperoleh deskripsi atau gambaran secara cermat mengenai fakta-fakta yang berkaitan dengan objek penelitian. Penelitian verifikative dilakukan untuk menghasilkan informasi ilmiah melalui pengujian hipotesis.

Metode penelitian yang digunakan adalah Explanatory Survey. Menurut Singarimbun (1995) penelitian survey adalah penelitian yang mengambil sampel dari satu populasi dan menggunakan kuesioner sebagai alat pengumpulan data yang pokok. Explanatory Survey merupakan penelitian survey yang dilakukan untuk menjelaskan hubungan antar variabel yang diteliti.

Populasi, Sampel dan Teknik Sampling

Populasi dalam penelitian ini adalah bisnis retail Perusahaan Pasangan Usaha PT. XYZ di Kotamadya Surakarta. Penelitian ini berorientasi pada bisnis retail yang dapat diklasifikasikan menjadi dua yaitu retail kecil dan retail besar. Sample yang digunakan ditentukan berdasarkan pada metode Gay, yaitu sejumlah 30 perusahaan dengan pertimbangan bahwa ukuran minimum sampel yang dapat diterima untuk penelitian deskriptif korelasional adalah tigapuluh (Umar, 2002). Dalam penelitian ini pengambilan sampel dilakukan dengan teknik purposive sampling dimana pengambilan sampel dilakukan berdasarkan pertimbangan perorangan atau pertimbangan peneliti (Sudjana, 1989).

Teknik Pengukuran Variabel

a. Variabel Dependen :

1. Relationship quality yang dimaksud adalah indikasi level yang tinggi dari kepuasan, kepercayaan dalam hubungan antara supplier dan dealer. Pengukuran menggunakan single item dan dinilai dengan menggunakan skala Likert dari sangat tidak setuju (skor 1) sampai sangat setuju (skor 5).

b. Variabel Independen:

2. Commitment, yang dimaksud adalah segala sesuatu yang dilakukan supplier untuk menepati janji-janjinya agar hubungan dengan dealer berjalan dengan baik. Jumlah pertanyaan sebanyak 7 item dan setiap item pertanyaan dinilai dengan menggunakan skala Likert dari sangat tidak setuju (skor 1) sampai sangat setuju (skor 5).

3. Trust, yang dimaksud dengan trust adalah kemampuan supplier untuk menepati halhal yang berkaitan dengan perjanjian yang telah disepakati dengan dealer. Jumlah pertanyaan sebanyak 8 item dan setiap item pertanyaan dinilai dengan menggunakan skala Likert dari sangat tidak setuju (skor 1) sampai sangat setuju (skor $5)$. 


\section{Analisis Deskriptif Variabel}

Dari tabel 1 dapat diketahui trust mempunyai kisaran nilai yang stabil. Hal tersebut dapat dilihat dari nilai rata-rata responden untuk variabel trust tidak jauh berbeda dengan nilai yang sering keluar. Trust mempunyai nilai terbesar 5,00 yang merupakan nilai tertinggi dari kemungkinan yang ada dan mempunyai nilai terendah 3,50. Dari nilai tersebut dapat disimpulkan bahwa responden mempunyai nilai atau persepsi yang tinggi untuk variabel trust.

Tabel 1. Tabel Frekuensi

Statistics

\begin{tabular}{|c|c|c|c|c|}
\hline & & RQ1 & $\mathrm{T}$ & C \\
\hline \multirow[t]{2}{*}{$\bar{N}$} & Valid & $\overline{31}$ & 31 & 31 \\
\hline & Missing & 0 & 0 & 0 \\
\hline \multicolumn{2}{|c|}{ Mean } & 4,39 & 4,1089 & 3,7281 \\
\hline \multicolumn{2}{|c|}{ Std. Error of Mean } & , 100 & ,07164 & ,06637 \\
\hline \multicolumn{2}{|c|}{ Median } & 4,00 & 4,0000 & 3,7143 \\
\hline \multicolumn{2}{|c|}{ Mode } & 4 & 4,00 & 3,71 \\
\hline \multicolumn{2}{|c|}{ Std. Deviation } & ,558 & 39888 & ,36951 \\
\hline \multicolumn{2}{|c|}{ Skewness } &,- 135 & ,744 & ,269 \\
\hline \multicolumn{2}{|c|}{ Std. Error of Skewness } & ,421 & ,421 & ,421 \\
\hline \multicolumn{2}{|c|}{ Range } & 2 & 1,50 & 1,57 \\
\hline \multicolumn{2}{|c|}{ Minimum } & 3 & 3,50 & 3,00 \\
\hline \multicolumn{2}{|c|}{ Maximum } & 5 & 5,00 & 4,57 \\
\hline \multicolumn{2}{|c|}{ Sum } & 136 & 127,38 & 115,57 \\
\hline
\end{tabular}

Sumber: Data Primer Diolah 2009

Dari tabel 1 juga dapat diketahui commitment mempunyai kisaran nilai yang stabil. Hal tersebut dapat dilihat dari nilai rata-rata responden untuk variabel commitment tidak jauh berbeda dengan nilai yang sering keluar. Commitment mempunyai nilai terbesar 4,57 dan mempunyai nilai terendah 3,00. Dari nilai tersebut dapat disimpulkan bahwa responden mempunyai nilai atau persepsi yang cukup tinggi untuk variabel commitment.

Relationship quality mempunyai kisaran nilai yang cukup stabil. Hal tersebut dapat dilihat dari nilai rata-rata responden untuk variabel relationship quality tidak jauh berbeda dengan nilai yang sering keluar. Relationship quality mempunyai nilai terbesar 5,00 yang merupakan nilai tertinggi dari kemungkinan yang ada dan mempunyai nilai terendah 3,0 . Dari nilai tersebut dapat disimpulkan bahwa responden mempunyai nilai atau persepsi yang tinggi untuk variabel relationship quality.

\section{Pengujian Hipotesis}

Analisis Path dilakukan dengan menggunakan Model Regresi untuk menjelaskan hubungan antar variabel. Dalam penelitian ini model Regresi dilakukan untuk menguji (1) pengaruh signifikan dari variabel independen terhadap variabel pemediasi, (2) pengaruh signifikan variabel pemediasi terhadap variabel dependen, (3) pengaruh signifikan variabel independen terhadap variabel dependen setelah adanya variabel pemediasi dalam hubungan tersebut.

1. Tahap I: Pengujian pengaruh trust terhadap relationship quality. Hasil dari analisis pengaruh variabel trust terhadap relationship quality ditunjukkan pada tabel 2. 
Tabel 2. Hasil Regression Analysis dengan Trust Sebagai Variabel Dependen

\begin{tabular}{|l|l|r|r|r|r|l|}
\hline Model & & $\begin{array}{c}\text { Sum of } \\
\text { Squares }\end{array}$ & Df & \multicolumn{1}{c|}{$\begin{array}{c}\text { Mean } \\
\text { Square }\end{array}$} & \multicolumn{1}{c|}{ F } & Sig. \\
\hline 1 & Regressi & 3,258 & 1 & 3,258 & 15,498 &, $000(\mathrm{a})$ \\
& on & 29 & 210 & & \\
& Residual & 6,097 & 29 & & & \\
& Total & 9,355 & 30 & & & \\
\end{tabular}

Sumber : Data primer diolah 2009

Dari hasil analisis regresi pada Tabel 2 menunjukkan bahwa pengaruh trust terhadap relationship quality adalah signifikan, karena signifikansinya sebesar $0,000(<0,05)$, artinya trust dapat digunakan untuk memprediksi relationship quality. Dengan demikian $\mathrm{H} 1$ yang menyatakan bahwa trust mempunyai pengaruh positif terhadap relationship quality didukung dalam penelitian ini.

2. Tahap II: Pengujian pengaruh commitment terhadap relationship quality. Hasil dari analisis pengaruh variabel commitment terhadap relationship quality ditunjukkan pada tabel 3.

Tabel 3. Hasil Regression Analysis dengan Commitment Sebagai Variabel Dependen

\begin{tabular}{|l|l|r|r|r|r|r|}
\hline Model & & $\begin{array}{c}\text { Sum of } \\
\text { Squares }\end{array}$ & df & \multicolumn{1}{c|}{$\begin{array}{l}\text { Mean } \\
\text { Square }\end{array}$} & \multicolumn{1}{c|}{ F } & Sig. \\
\hline 1 & Regressi & 2,376 & 1 & 2,376 & 9,874 &, $004(\mathrm{a})$ \\
& on & 29 &, 241 & & \\
& Residual & 6,979 & 29 & & \\
& Total & 9,355 & 30 & & & \\
\hline
\end{tabular}

Sumber : Data primer diolah 2009

Dari hasil analisis regresi pada Tabel 3 menunjukkan bahwa pengaruh commitment terhadap relationship quality adalah signifikan, karena signifikansinya sebesar 0,004 (< 0,05 ), artinya commitment dapat digunakan untuk memprediksi relationship quality. Dengan demikian $\mathrm{H} 2$ yang menyatakan bahwa commitment mempunyai pengaruh positif terhadap relationship quality didukung dalam penelitian ini.

3. Tahap III: Pengujian pengaruh commitment sebagai pemediasi dalam hubungan antara trust dengan relationship quality. Hasil dari analisis pengaruh commitment sebagai pemediasi dalam hubungan antara trust dengan relationship quality ditunjukkan pada tabel IV.16, IV.17, dan IV.18.

a. Pengujian pengaruh trust terhadap commitment

Tabel 4. Hasil Multiple Regression Analysis dengan Commitment Sebagai Variabel Dependen

\begin{tabular}{|l|c|r|r|r|r|r|}
\hline Model & & \multicolumn{2}{|c|}{$\begin{array}{c}\text { Unstandardized } \\
\text { Coefficients }\end{array}$} & $\begin{array}{c}\text { Standardized } \\
\text { Coefficients }\end{array}$ & \multicolumn{1}{c|}{ T } & Sig. \\
\hline & & \multicolumn{1}{c|}{ B } & Std. Error & \multicolumn{1}{c|}{ Beta } & & \\
\hline 1 & (Constant) & 1,524 &, 579 & & 2,633 &, 013 \\
& $\mathrm{~T}$ &, 536 &, 140 &, 579 & 3,825 &, 001 \\
\hline
\end{tabular}

Sumber : Data primer diolah 2009

Dari hasil analisis regresi tabel 4 ditemukan bahwa trust berpengaruh signifikan pada commitment ( $p$-value $<0,05$ ) dengan koefisien regresi $=0,536$. 
b. Pengujian pengaruh trust terhadap relationship quality

Tabel 5. Hasil Multiple Regression Analysis dengan Relationship Quality Sebagai Variabel Dependen

\begin{tabular}{|c|c|c|c|c|c|c|}
\hline \multirow[t]{2}{*}{ Model } & & \multicolumn{2}{|c|}{$\begin{array}{l}\text { Unstandardized } \\
\text { Coefficients }\end{array}$} & \multirow{2}{*}{$\begin{array}{c}\text { Standardized } \\
\text { Coefficients } \\
\text { Beta }\end{array}$} & \multirow[t]{2}{*}{$\mathrm{T}$} & \multirow[t]{2}{*}{ Sig. } \\
\hline & & B & Std. Error & & & \\
\hline 1 & $\begin{array}{l}\text { (Constant) } \\
T\end{array}$ & $\begin{array}{l}.992 \\
826\end{array}$ & $\begin{array}{l}.866 \\
.210\end{array}$ & ,590 & $\begin{array}{l}1,146 \\
3,937\end{array}$ & $\begin{array}{l}261 \\
, 000\end{array}$ \\
\hline
\end{tabular}

Sumber : Data primer diolah 2009

Dari hasil analisis regresi tabel 5 ditemukan bahwa trust berpengaruh signifikan pada relationship quality $(\mathrm{p}$-value $<0,05)$ dengan koefisien regresi $=0,826$.

c. Pengujian pengaruh trust dan commitment sebagai variabel mediasi terhadap relationship quality

Tabel 6. Hasil Multiple Regression Analysis Antara trust dan commitment terhadap relationship quality

\begin{tabular}{|c|c|c|c|c|c|c|}
\hline \multirow[t]{2}{*}{ Model } & & \multicolumn{2}{|c|}{$\begin{array}{c}\text { Unstandardized } \\
\text { Coefficients }\end{array}$} & \multirow{2}{*}{$\begin{array}{c}\text { Standardized } \\
\text { Coefficients } \\
\text { Beta }\end{array}$} & \multirow[t]{2}{*}{$\mathrm{T}$} & \multirow[t]{2}{*}{ Sig. } \\
\hline & & B & Std. Error & & & \\
\hline 1 & $\begin{array}{l}\text { (Constant) } \\
\text { C } \\
\text { T }\end{array}$ & $\begin{array}{l}.430 \\
, 369 \\
628\end{array}$ & $\begin{array}{l}951 \\
.274 \\
.254\end{array}$ & $\begin{array}{l}244 \\
449\end{array}$ & $\begin{array}{r}, 452 \\
1,346 \\
2,475\end{array}$ & $\begin{array}{l}654 \\
, 189 \\
, 020\end{array}$ \\
\hline
\end{tabular}

Sumber : Data primer diolah 2009

Dari tabel 6 ditemukan bahwa commitment tidak berpengaruh signifikan pada $R Q(p$ value $>0,05$ ) dengan koefisien regresi $=0,369$. Ditemukan direct effect T sebesar 0,628 yang lebih kecil dari 0,826 . Pengaruh variabel independent trust terhadap variabel dependen relationship quality berkurang dan signifikan ( $p$-value $<0,05$ ). Hal ini mengindikasikan terjadi mediasi variabel commitment terhadap pengaruh trust ke relationship quality.

\section{PEMBAHASAN}

\section{Pengaruh trust terhadap relationship quality}

Hasil analisis regresi menunjukkan bahwa trust mempunyai pengaruh positif terhadap relationship quality. Meskipun dalam lingkup jenis industri dan negara yang berbeda, namun dengan diterimanya hipotesis pertama tersebut, yaitu adanya pengaruh positif trust terhadap relationship quality, maka penelitian yang dilakukan pada perusahaan pasangan PT. XYZ sebagai lembaga pembiayaan di Surakarta ini mendukung penelitian sebelumnya yang dilakukan oleh Amy Wong dan Amrik Sohal (2002) bahwa trust dapat memberikan dampak penting dalam penetepan kualitas hubungan dengan level yang lebih tinggi.

Implikasi manajerial bagi PT. XYZ adalah bahwa untuk dapat meningkatkan kualitas hubungan dengan Perusahaan Pasangan Usaha (PPU), PT. XYZ harus dapat membentuk dan memperoleh kepercayaan dari PPU. Rahardian dan Sunaryo (2006) mengungkap bahwa kepercayaan/trust terbentuk dari beberapa variabel, yaitu kemampuan adaptasi, shared value, komunikasi, opportunistic behavior, kepuasan dan kerjasama (cooperation). Beberapa variabel tersebut juga diungkap dalam masukan-masukan responden terkait 
variabel trust, misalnya masukan tentang mengenali mitra lebih dekat. Hal ini dapat dilakukan melalui peningkatan komunikasi dengan PPU dan kesediaan untuk beradaptasi. Demikian pula dengan masukan untuk mempertahankan kualitas layanan dan mengutamakan kepuasan nasabah yang terkait erat dengan pencapaian satisfaction.

\section{Pengaruh commitment terhadap relationship quality}

Hasil analisis regresi menunjukkan bahwa commitment mempunyai pengaruh positif terhadap relationship quality. Meskipun dalam lingkup jenis industri dan negara yang berbeda, namun dengan diterimanya $\mathrm{H} 2$ yaitu adanya pengaruh positif commitment terhadap relationship quality, maka penelitian yang dilakukan pada perusahaan pasangan PT. XYZ sebagai lembaga pembiayaan di Surakarta ini mendukung penelitian sebelumnya yang dilakukan oleh Amy Wong dan Amrik Sohal (2002) bahwa komitmen adalah suatu yang penting bagi pembangunan dan pemeliharaan kualitas sebuah hubungan.

Implikasi manajerial bagi PT. XYZ terkait pengaruh komitmen pada relationship quality adalah bahwa untuk dapat menghasilkan kualitas hubungan yang baik dengan Perusahaan Pasangan Usaha, PT. XYZ harus membentuk dan memberikan komitmen penuh kepada PPU. Studi yang dilakukan Rahardian dan Sunaryo (2006) juga mengungkap beberapa variabel pembentuk komitmen adalah kemampuan adaptasi, relationship bonds, relationship termination cost, shared value, komunikasi, opportunistic behavior, kepuasan dan kerjasama (cooperation). Variabel-variabel tersebut juga telah terungkap dalam masukan-masukan responden terkait variabel komitmen dalam penelitian ini, misalnya program yang tidak memberatkan mitra yang dapat berdampak pada pemutusan kerjasama (relationship termination cost). Masukan untuk menjadikan PPU sebagai mitra bisnis sangat erat terkait dengan kemampuan adaptasi dan relationship bonds antara PT. $\mathrm{XYZ}$ dengan PPU.

\section{Mediasi commitment terhadap pengaruh trust ke relationship quality}

Hasil path analysis menunjukkan bahwa terjadi mediasi variabel commitment terhadap pengaruh trust ke relationship quality. Hal ini sejalan dengan studi Wong (2002) yang menguji pengaruh trust dan commitment terhadap relationship quality dalam hubungan antara seller dengan customer: sebuah studi empiris pada bisnis retail di Victoria, Australia. Implikasi manajerial dari temuan ini adalah bahwa trust yang dibangun oleh PT. XYZ harus didukung dengan adanya komitmen yang kuat untuk dapat memediasi trust dalam menghasilkan sebuah kualitas hubungan yang baik antara PT. XYZ dengan PPU.

\section{KESIMPULAN}

Berdasar hasil penelitian dapat ditarik kesimpulan mengenai pengaruh trust dan commitment terhadap relationship quality adalah sebagai berikut:

1. Ditemukan bahwa trust mempunyai nilai yang signifikan terhadap relationship quality. Artinya trust mempunyai pengaruh yang positif terhadap relationship quality dalam hubungan antara Perusahaan Pasangan Usaha dengan PT. XYZ sebagai lembaga pembiayaan non bank di Surakarta.

2. Ditemukan bahwa commitment mempunyai nilai yang signifikan terhadap relationship quality. Hal ini berarti commitment mempunyai pengaruh yang positif terhadap relationship quality dalam hubungan antara Perusahaan Pasangan Usaha dengan PT. XYZ sebagai lembaga pembiayaan non bank di Surakarta.

3. Uji pengaruh trust terhadap relationship quality dengan commitment sebagai pemediasi menemukan bahwa dengan adanya commitment sebagai pemediasi menjadikan tingkat signifikansi trust terhadap relationship quality menurun. Dengan kata lain terdapat pengaruh mediasi variabel commitment terhadap pengaruh trust ke relationship quality.. 


\section{KETERBATASAN}

Dalam penelitian ini terdapat beberapa keterbatasan antara lain:

1. Dalam penelitian tentang pengaruh trust dan commitment pada relationship quality dalam hubungan antara supplier dengan dealer ini berorientasi pada PT. XYZ sebuah lembaga pembiayaan di Surakarta sebagai lingkup penelitiannya dan dengan menggunakan 30 perusahaan pasangan usaha sebagai sampelnya. Dengan lingkup penelitian hanya pada PT. XYZ yang merupakan lembaga keuangan saja maka mengakibatkan hasil penelitian ini belum bisa digeneralisasikan untuk semua jenis perusahaan. Sedangkan pengambilan jumlah sampel yang minimum disebabkan karena keterbatasan waktu dalam penelitian ini.

2. Penelitian ini hanya berorientasi pada persepsi responden. Dengan demikian muncul kesan subjektifitas responden, terlebih dengan kecondongan jawaban responden pada salah satu sisi kurva normal.

3. Penelitian tentang faktor-faktor yang berpengaruh pada relationship quality pada hubungan supplier dengan dealer ini baru menggunakan dua faktor yaitu trust dan commitment sebagai variabel independen, masih ada faktor-faktor lain yang dapat mempengaruhi relationship quality antara supplier dengan dealer. Seperti information sharing, partners reputation, perceived conflict, communication dan lain-lain.

\section{SARAN}

Dari hasil penelitian yang telah dilakukan, maka saran-saran yang dapat diberikan sebagai implikasi dari penelitian adalah :

1. Dari hasil analisis ditemukan bahwa tingkat kepercayaan dan komitmen mempunyai pengaruh yang signifikan terhadap kualitas hubungan dalam sebuah kerjasama antara PT. XYZ dengan perusahaan pasangan usahanya. Dengan demikian baik PT. XYZ maupun perusahaan pasngan usaha diharapkan untuk lebih memperhatikan faktorfaktor tersebut dalam membina sebuah hubungan bisnis yang lebih baik.

2. PT. XYZ dapat menindaklanjuti penelitian ini dengan melakukan analisis perbandingan menggunakan data kinerja riil masing-masing responden berdasar penilaian PT. XYZ. Dengan demikian diharapkan hasil penelitian dapat lebih objektif.

3. Penelitian mendatang sebaiknya memperluas area survei dengan jumlah sampel yang lebih banyak. Selain itu penelitian mendatang dapat dilakukan pada objek penelitian yang berbeda pada industri-industri lain baik industri jasa lainnya, manufaktur ataupun industri lainnya.

4. Penelitian yang akan datang sebaiknya menggunakan atau menambah variabel yang lain yang mempengaruhi trust dan commitment pada hubungan antara supplier dengan dealer yang belum dianalisis dalam penelitian ini. Misalkan : asset specificity, behavioral uncertainly, information sharing, partners reputation, perceived conflict dan lain-lain.

\section{DAFTAR PUSTAKA}

Burt, DN. and Doyle, MF. 1993. The American Keiretsu: A Strategic Weapon for Global Competitiveness. Business One Irwin, Homewood.

Cousineau, Mellissa et al. 2004. Supplier Source Integration In A Large Manufacturing Company. Supply chain Management Journal. Vol (9). No.1:110-117. 
Ellram, LM. 1995. Partnering Pittfalls and Success Factors. International Journal of Purchasing and Materials Management Vol 31 No 2 p 36-44.

Ford, D. Gadde, LE., Hakansson, H., Lundgren, A., Snehota, I., Turnbull, P., and Wilson, D. 1998. Managing Business Relationships, John Wiley \& Sons, New York.

Frohlich, Markam T, and Roy Westbrook. 2001. Arch of Integration: an International Study of Supply chain Strategies. Journal of Operation Management. Vol(19): 185-200.

Hakansson, H and Snehota, I. 1995. Developing Relationships in Business Networks. International Thomson Business Press, London.

Kwon, Ik-Whan G. And Taewon Suh, May 2004, Factors Affecting the Level of Trust and Commitmen in Supply Chain Management, The Journal of Supply Chain Management, Page 4 - 14.

Landeros, R. and Monczska, RM. 1989. Cooperative buyer/seller relationships and a firm's competitive posture. International Journal of Purchasing and Materials Management Vol 25 No 3, Page 9-18.

Lorange, P. and Roos, J. 1991. Strategic Alliances: Formation, Implementation and Evolution, Basil Blackwell, Oxford.

Morgan, R. And Hunt, S. 1994. The Commitment-Trust Theory of Relationship Marketing. Journal of Marketing. Vol 58 No 3, o 20-38

Narasimhan, Ram dan Das Ajay. 2001. The Impact of Purchasing Integration and Practices on Manufacturing Performance. Journal of Operation Management 19: 593-609.

Schurr, P. and Ozanne, JL. 1985. Influences of exchange processes: buyer's preconceptions of a seller's trustworthiness and bargaining toughness. Journal of Consumer Research Vol 11, March p. 939-53

Smeltzer, L. 1997. The Meaning and Origin of Trust in Buyer-Supplier Relationship. . International Journal of Purchasing and Materials Management Vol 33 No 1 p 40-8.

Umar, Husein. 2002. "Riset Pemasaran dan Perilaku Konsumen". Jakarta Business Research Center. Jakarta: PT. Gramedia Pustaka Utama.

Wong, A and Sohal, A. 2002. An Examination of the relationship between trust, commitment and relationship quality. International journal of retail and distribution management, vol 30, number 1, p 34-50

Wu, Guohua. 2005. The Mediating Role of Perceived Interactivity in the Effect of Actual Interactivity on Attitude toward the Website. Journal of Interactive Advertising, Vol. 5, Number 2, Page 1-14

Zineldin, M, Johannisson, B. and Dandridge, T. 1997. Strategic Relationship Management: a Multi Dimensional Perspective. Almqvist \& Wiksell International.

Zineldin, M. 1998. Exploring the Common Ground of Total Relationship Management (TRM) and Total Quality Management. Management Decision. Vol 32 No 11/12 p 38-64.

Zineldin, Mosad and Patrik Jonsson, 2000, An Examination Of Main Factors Affecting Trust/Commitment In Supplier-Dealer Delationship: An Empirical Study Of The Swedish Wood industry, The TQM Magazine, Vol 12, Page 245-265. 